\title{
Ultrastructural Changes in the Placental Membrane in Pregnancies Associated with Diabetes
}

\author{
Cambios Ultraestructurales en la Membrana Placentaria en Embarazos Asociados con la Diabetes
}

\author{
Ranjana Verma; Mishra, S. \& Jagat Mohini Kaul
}

VERMA, R.; MISHRA, S.; KAUL, J. M. Ultrastructural changes in the placental membrane in pregnancies associated with diabetes. Int. J. Morphol., 29(4):1398-1407, 2011.

SUMMARY: Placenta is the most accurate record of the infant prenatal experience. If the placenta is examined minutely after delivery, it provides much insight into the prenatal health of the baby and the mother. The weight of placenta is higher in diabetic pregnancy in comparison to the normal pregnancy. To study the cellular changes that might contribute to more weight of placenta in diabetic pregnancies, light microscopic and electron microscopic analysis was performed. Twenty singleton pregnancies complicated with Gestational diabetes mellitus (12 controlled on diet, 8 controlled on insulin) were selected and compared to control group. Tissue sections were processed and analyzed. The placenta of diabetic pregnancies showed no abnormality on gross observation but light microscopic examination revealed, lesions like syncytial knots, fibrinoid necrosis, villous edema, villous fibrosis and capillary proliferation. Transmission electron microscopic examination (TEM) showed changes in almost all the layers of the placental membrane i.e. synctiotrophoblast, cytotrophoblast, trophoblastic basement membrane and fetal capillaries. These changes were observed in the placenta of both groups of patients whether blood sugar level was controlled by diet or insulin, but to different degree. It indicates that control of hyperglycemia only partially prevents the development of placental abnormalities which must be due to some other constituent factor of diabetic state.

KEY WORDS: Gestational diabetes mellitus; Transmission electron Microscopy; Placental membrane.

\section{INTRODUCTION}

Diabetes is now a major health concern in our society. According to the centers for disease control and prevention, from 1980 to 2005, the crude incidence of diagnosed diabetes has increased from 3.3 per 1000 to 7.4 per 1000 i.e by $124 \%$. Studies suggest that the prevalence of diabetes mellitus (DM) among women of childbearing age is increasing due to more sedentary lifestyles, changes in diet, and the virtual epidemic of childhood and adolescent obesity that is presently evolving in India. Gestational diabetes mellitus (GDM) is defined as glucose intolerance of variable degree with onset or first recognition during pregnancy. Abnormal maternal glucose tolerance occurs in 3-10\% of pregnancies in Indian population (Dutta, 2004).

Maternal diabetes mellitus exposes the fetus to the risk of macrosomia, congenital malformations, intrauterine growth retardation and difficult labour (Fletcher, 1981). The neonatal metabolic problems are hypoglycemia and hypocalcaemia. All these conditions may be related to reduced placental perfusion and decreased arterial oxygen saturation attributing to placental abnormalities. Therefore, the placenta of diabetic women has gained much interest showing several pathological changes.

In term pregnancy, the placental membrane is extremely thin, approximately $0.002 \mathrm{~mm}$ in thickness, separating fetal blood from maternal blood. The five layers of this attenuated membrane, i.e., the fetal endothelium, its basement membrane, the reticular network and the syncytium with its basement membrane, however, persist until the end of pregnancy. The cytotrophoblast is usually observed in the thicker portions of the villi.

Various morphological lesions have been reported in the different layers of the placental membrane like syncytial knot formation (Burstein et al., 1957; Clavero-Nunez, 1963; Dashkevich \& Sechonov, 1664), increased thickness of

\footnotetext{
* Assistant Professor, Department of Anatomy, Maulana Azad Medical College, New Delhi, India.

** Professors, Department of Anatomy, Maulana Azad Medical College, New Delhi, India.

**** Director Professor \& Head of Department, Department of Anatomy, Maulana Azad Medical College, New Delhi, India.
} 
vasculosyncytial membrane (Burstein et al., 1963; Holzner \& Thalhammer, 1965), villous fibrinoid necrosis (Burstein et al., 1957; Sani \& Bottigliani, 1964), villous immaturity (Horky, 1964; Hughes, 1961), trophoblastic hyperplasia, accumulation of glycogen and villous edema (al-Okail \& al-Attas, 1994). Some authors had also reported no changes in the placental membrane (Cardwell, 1953; Marksheed et al., 2002).

There are different views in literatures regarding the ultrastructural changes in the placental membrane in diabetic pregnancy, changes like thickening of basal membrane of the trophoblast, separation of basal membrane in the basal capillaries, distension and proliferation of endothelial cells (Pietryga et al., 2004). Increased vascularization and glycogen accumulation within the stromal cells, which corresponds to the higher glycogen content of diabetic placentas has been also reported (Asmussen, 1982). Another study also revealed focal thickening of the trophoblastic basement membrane, patchy areas of syncytiotrophoblastic necrosis along with marked cytotrophoblastic hyperplasia. Occasional cytotrophoblast cells also showed degenerative changes (Jones \& Fox, 1976).

These confusing results may be due to the improper case selection where Gestational diabetes mellitus (GDM) with superadded complications like pre-eclamptic toxemia or intrauterine fetal death; may have obscured the significant changes in the diabetic placentas (Jones \& Fox). Study of diabetic placentas, in which these complicating factors will be excluded, may yield a moderately consistent pattern of changes at microscopic levels.

In order to avoid some of the inadequacy of earlier studies, we have selected well characterized group of diabetic pregnancies without any superadded complications and placentas were scanned for light and electron microscopic changes.

\section{MATERIAL AND METHOD}

Twenty five placenta of full term pregnancy (37-42 weeks) delivered either by vaginal route or by caesarian section were collected from the labour room, Lok Nayak Hospital, New Delhi. The range of age of these mothers varied from 20 years to 38 years and the parity from 1 to 5 . The total number of placenta from diabetic pregnancies (GDM) without any other associated disease was twenty, in which twelve diabetics were on diet control and eight on insulin. In all cases, blood sugar level was controlled either by diet or by insulin therapy. The number of placentas controlled on insulin was less due to non availability of cases. Five control placentas of normal pregnancy were matched for age and parity (Table I).
Table I. Showing total number of placentas studied from case and control group.

\begin{tabular}{llc}
\hline Group of patients & $\begin{array}{c}\text { Number of } \\
\text { placentas }\end{array}$ \\
\hline Control & Controlled on & 5 \\
Gestational Diabetes & 12 \\
$($ GDM $)$ & Controlled on & 8 \\
\hline
\end{tabular}

The placentas were weighed after collection from the labour room. The gross placental characteristics were noted. Immediately two small samples of tissue were taken out from the centre of placenta, one for light microscopy fixed in $10 \%$ formalin, another for electron microscopy fixed in glutaraldehyde phosphate buffer.

For light microscopy, two $\mathrm{cm}$. wedge of tissue was taken from the centre of each placenta and fixed in $10 \%$ formalin for one week. The tissue was dehydrated and processed for paraffin embedding. Serial sections of 7 micron were generated with the help of rotatory microtome. The tissue sections were stained with hematoxylene and eosin stain. Histological appearance of the terminal villi of placenta was observed under light microscope.

For electron microscopy tissue sample of $1 \mathrm{~mm}$ cube was taken from the centre of placenta fixed immediately in Karnovsky fixative $(2.5 \%$ glutaraldehyde-formaldehyde mixture in phosphate buffer) at $\mathrm{pH}$ 7.4. After several rinses in phosphate buffer, the specimens were postfixed in osmium tetraoxide. Then dehydration was done with acetone and embedded in Araldite. Before ultrathin sectioning, semithin sections were taken $(0.5-2$ micron) and stained with $1 \%$ toluidine blue solution for scanning the tissue under the light microscope. After locating the areas, ultrathin sections of 60 to $80 \mathrm{~nm}$ thickness were generated and double-stained with uranyl acetate and lead citrate. The tissues were picked up on the grid and scanned under transmission electron microscope. All the layers of the placental membranesyncytiotrophoblast, cytotrophoblast villous stroma and fetal capillary were scanned for their metabolic activity, thickening of basement membrane, edema, deposition of glycogen and any other abnormality.

\section{RESULTS}

As the human placenta is hemochorial, the fetal blood is separated from the maternal blood by placental membrane through which exchange occurs. At term the placental membrane consist of the syncytium with its basement membrane, the reticular network and the fetal endothelium 
with its basement membrane. The cytotrophoblast is exceptionally observed in the thicker portions of the villi. In the diabetic pregnancy, changes were observed in almost all the layers of the placental membrane.

Light microscopy (Table II). Under light microscopy, the terminal villi of control placenta showed very thin placental membrane composed of syncytotrphoblast with its basement membrane, the reticular network and fetal endothelium, with its basement membrane. The placentas of diabetes controlled on diet, showed minimal changes in the terminal villi like more numbers of syncytial knots, fibrinoid necrosis, resembling more to the control placenta. By contrast, the terminal villi in the placentas of GDM controlled on insulin showed a varying degree of changes, like increased number of syncytial knots (Fig.1a) and more number of cytotrophoblast. The stroma of the villi demonstrated villous edema (Fig. 1b) and fibrinoid necrosis (Fig.1c) and fibrosis (Fig.1d). Fetal capillary proliferation (Fig.1e) was also observed in the few placentas.
Electron microscopy (Table III). Under electron microscope the different layers of placental membrane were seen.

Syncytium: In the control placenta (Fig. 2a) the surface of the syncytium covering the villi in the many regions had well developed microvilli. Syncytial nuclei were markedly electron dense especially in the periphery with prominent nucleoli. The cytoplasm contained mitochondria, golgi apparatus, rough endoplasmic reticulum, polysome and lysosomes. In diabetic pregnancy controlled on diet, showed variable degree of dialatation of rough endoplasmic reticulum and glycogen deposits in few cases. The diabetes controlled on insulin showed variable degree of dialatation of rough endoplasmic reticulum (Fig. 2b) in more than 50\% of cases. Glycogen deposits were seen in the syncytium in some placentas (Fig. 2c). In few cases, small focal areas of syncytial necrosis characterized by - loss of cytoplasmic organelle, decreased density of the cytoplasmic matrix was noted (Fig. 2d).

Table II. Showing light microscopic changes in the placental membrane of diabetic placentas controlled on the diet and insulin therapy.

\begin{tabular}{lcccc}
\hline Placental Membrane & Control (5) & GDM controlled on diet (12) & GDM controlled on insulin (8) \\
\hline Syncytial knots & & + & + & ++ \\
Cytotrophoblast & & Scanty & More & More \\
Villous Stroma & Edema & - & + & +++ \\
& Fibrinoid necrosis & - & + & ++ \\
& Villous fibrosis & - & - & ++ \\
Fetal capillary proliferation & - & + & + \\
\hline
\end{tabular}

(- absent, + mild, ++ moderate, +++ severe).

Table III. Showing electron microscopic changes in the diabetic placentas controlled on the diet and insulin therapy.

\begin{tabular}{|c|c|c|c|c|}
\hline Placental Membrane & & $\begin{array}{c}\text { Control } \\
(n=5)\end{array}$ & $\begin{array}{l}\text { GDM controlled } \\
\text { on diet }(n=12)\end{array}$ & $\begin{array}{l}\text { GDM controlled } \\
\text { on insulin }(n=8)\end{array}$ \\
\hline \multirow[t]{3}{*}{ Syncy tiotrophoblast } & Dialatation of RER & - & + & ++ \\
\hline & Syncytial necrosis & - & - & + \\
\hline & Glycogen deposits & - & + & + \\
\hline \multirow[t]{4}{*}{ Cytotrophoblast } & Number & + & ++ & +++ \\
\hline & Active cytotrophoblast & + & + & ++ \\
\hline & Degenerative changes & - & - & + \\
\hline & Glycogen deposits & - & + & + \\
\hline Trophoblastic Basement Membrane & Thickness & $\mathrm{N}$ & + & + \\
\hline \multirow[t]{2}{*}{ Villous core } & Edema & - & + & +++ \\
\hline & Glycogen deposits & - & + & + \\
\hline \multirow[t]{2}{*}{ Foetal Capillary } & Basement Membrane & $\mathrm{N}$ & - & - \\
\hline & Glycogen deposits & - & + & + \\
\hline
\end{tabular}

( $\mathrm{N}$ - no significant change, - absent, + mild, ++ moderate, +++ severe). 


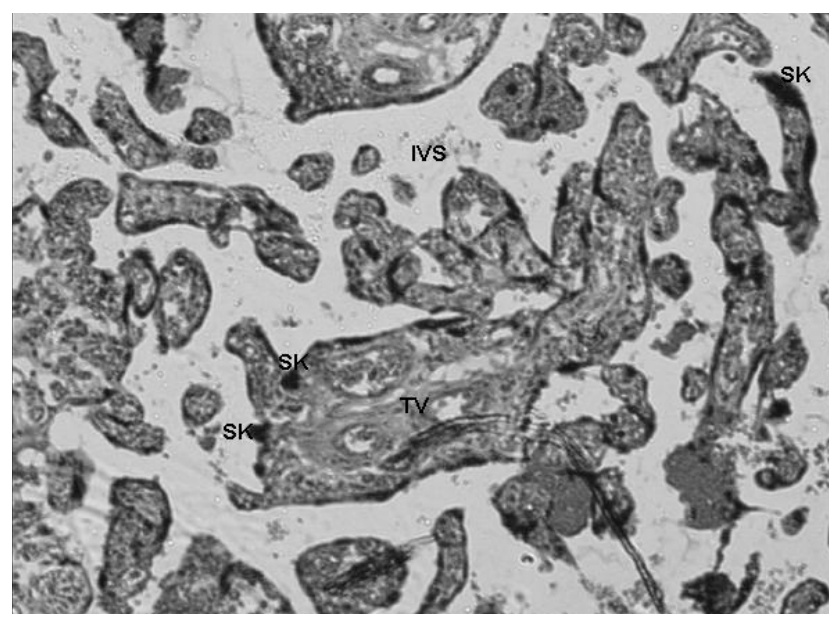

Fig.1a. Syncytial Knots (H\&E 40X).

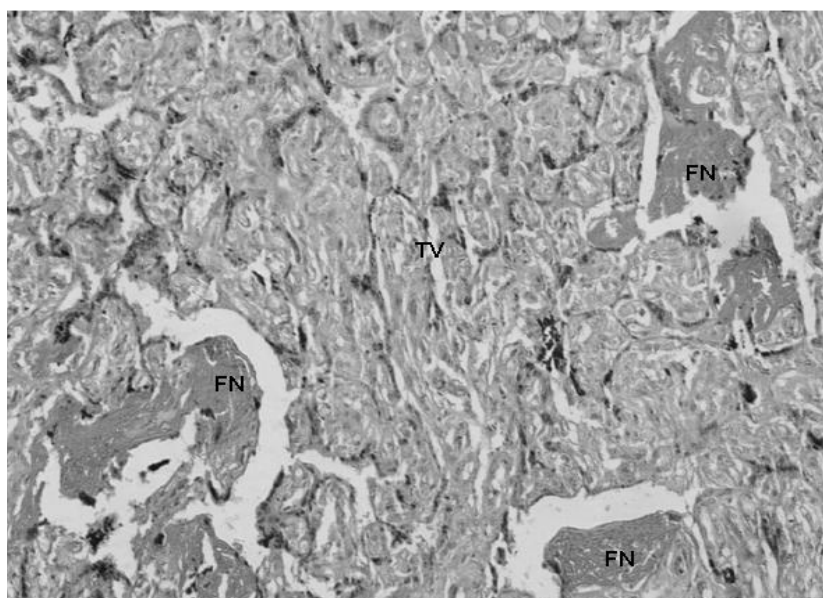

Fig. 1c. Fibrinoid necrosis (H\&E 40X.

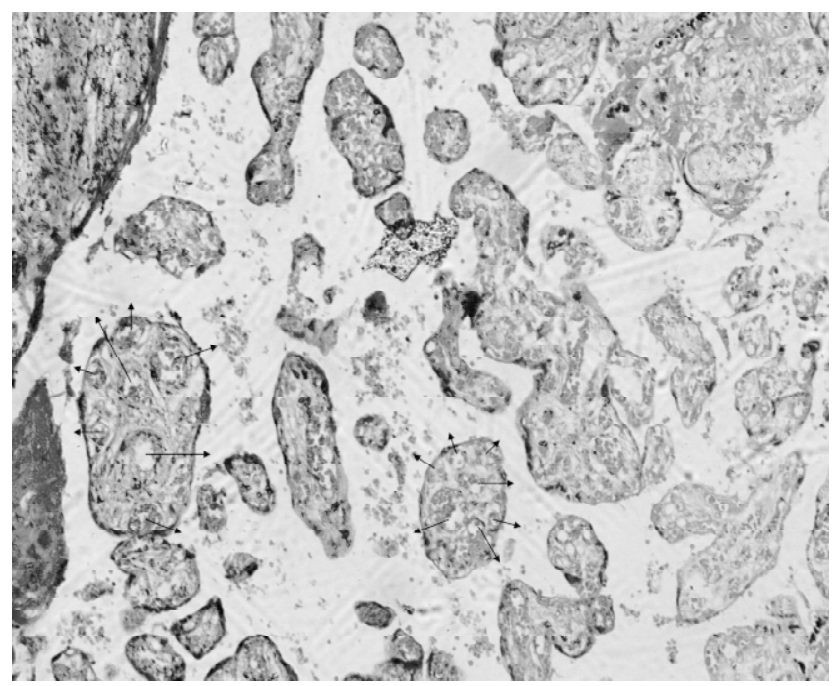

Fig. 1e. Capillary proliferation (H\&E 40X)

Cytotrophoblast: In control placenta (Fig. 2a), usually at term the cytotrophoblast is exceptionally observed in the thicker portions of the villi. The cytoplasm of the cytotrophoblast

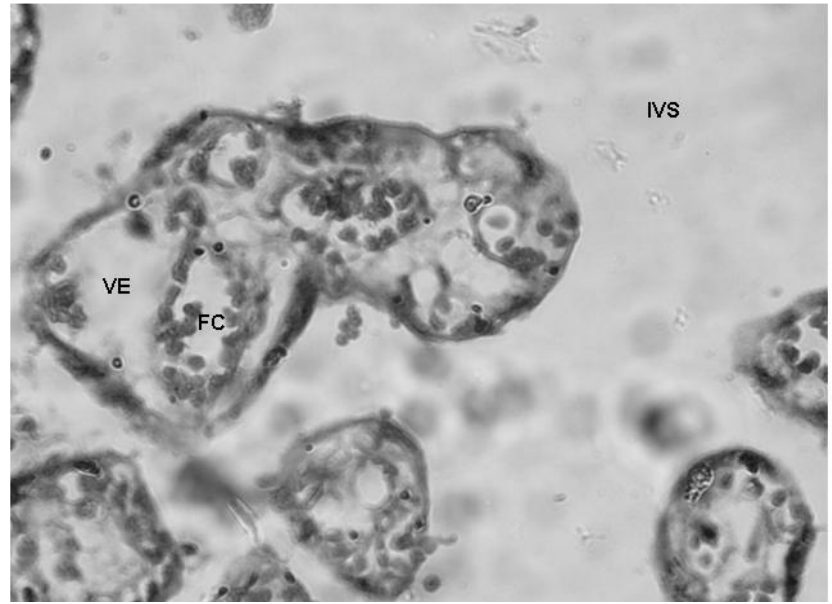

Fig. 1b. Villous edema (H\&E 40X).

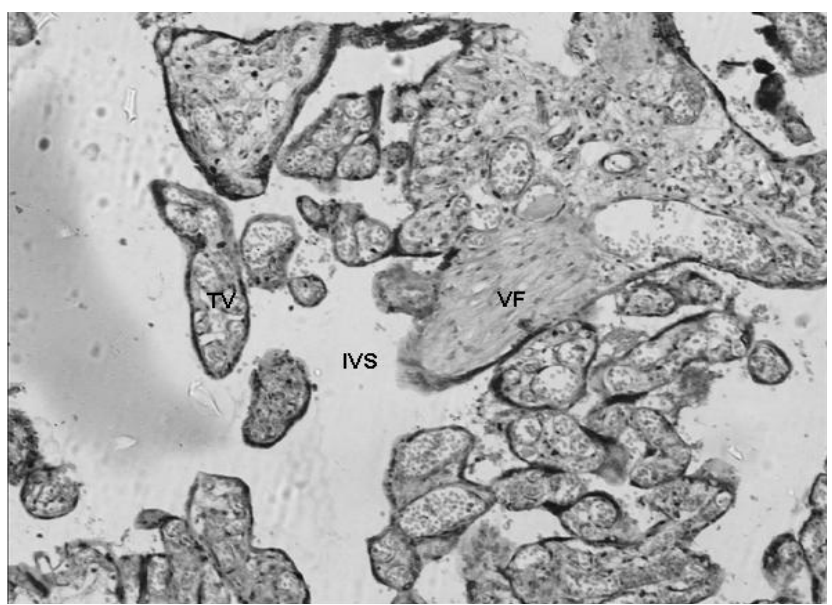

Fig. 1d. Villous fibrosis (H\&E 40X).

Fig. 1. Lightmicroscopy of a terminal villi in placenta of a woman with gestational diabetes mellitus.

(SK- Syncytial Knots, IVS- Intervillous space, TV- Terminal Villi, VE- Villous Edema, FN- Fibrinoid necrosis, VF- Villous Fibrosis, FC- Fetal Capillary)

showed the moderate electron density and contained larger mitochondria, golgi apparatus. The endoplasmic reticulum is poorly developed, possessing few attached ribosomes. In diabetic pregnancy controlled with diet, increased number of the cytotrophoblast was seen. In almost all placentas the cytotrophoblastic cells were of active type and contained conspicuous golgi apparatus, secretory granules, rough endoplasmic reticulum, smooth endoplasmic reticulum, mitochondria (Fig. 3a). In diabetic pregnany controlled on insulin, number of active cytotrophoblast was more. In some cases, double nuclei were seen in the cytotrophoblast with abundance of cytoplasmic organelle (Fig. 3b). Few 


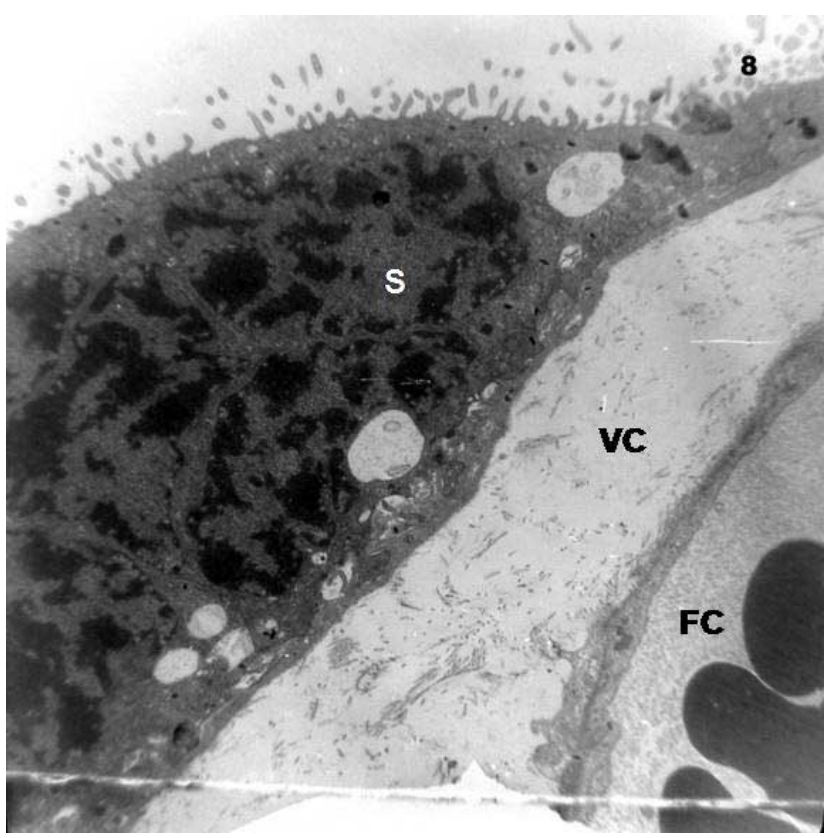

Fig. 2a. Control placental membrane (X-1950.

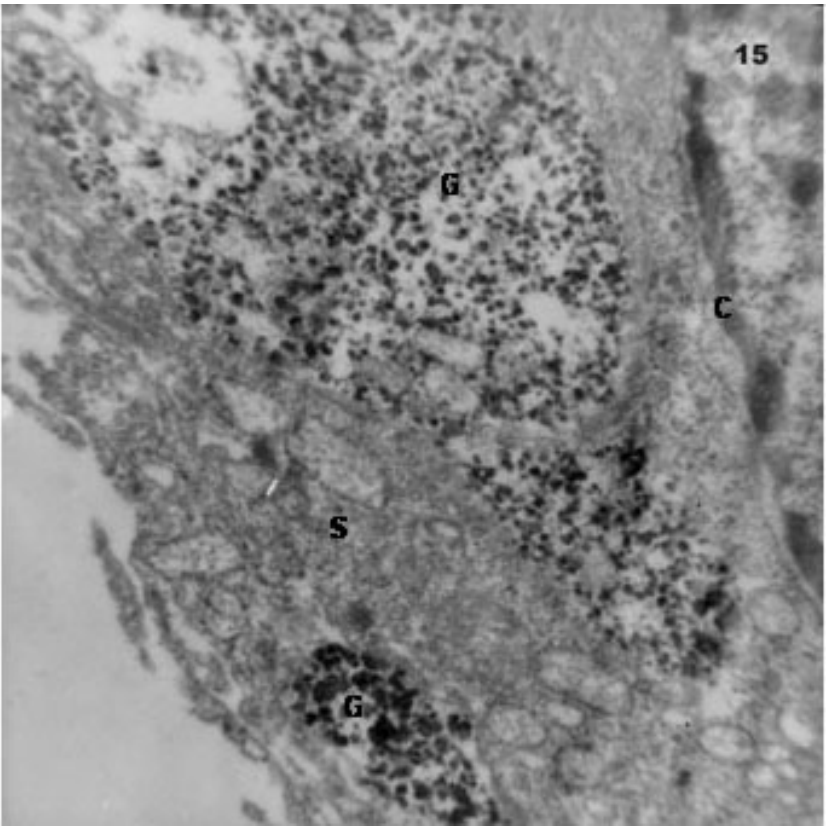

Fig. 2c. Glycogen deposits (X-6300).

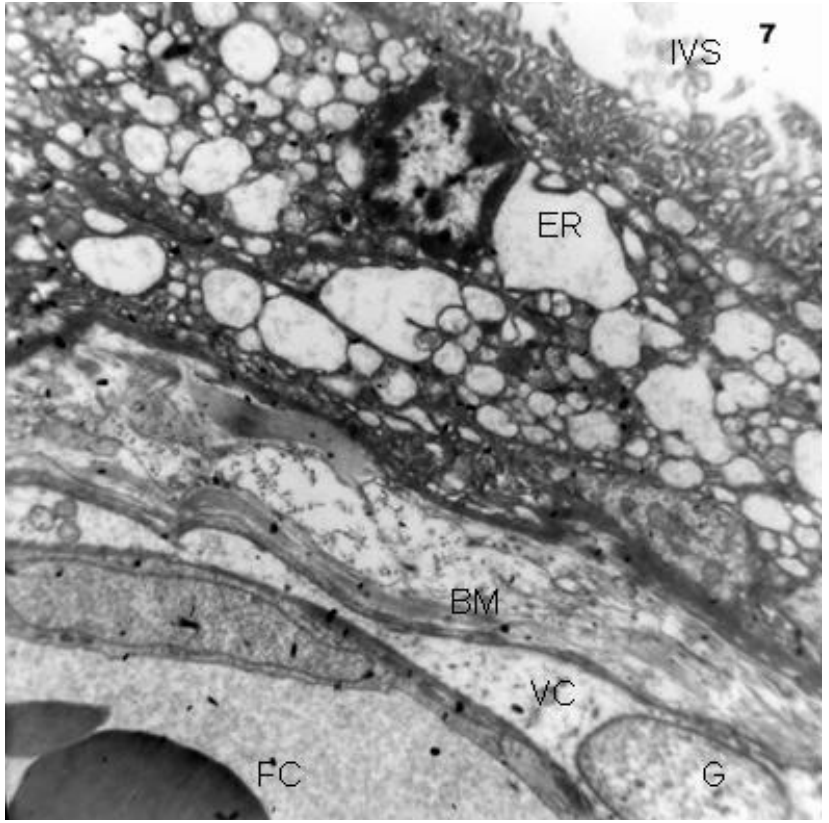

Fig. 2b. Dilatation of RER (X-1950).

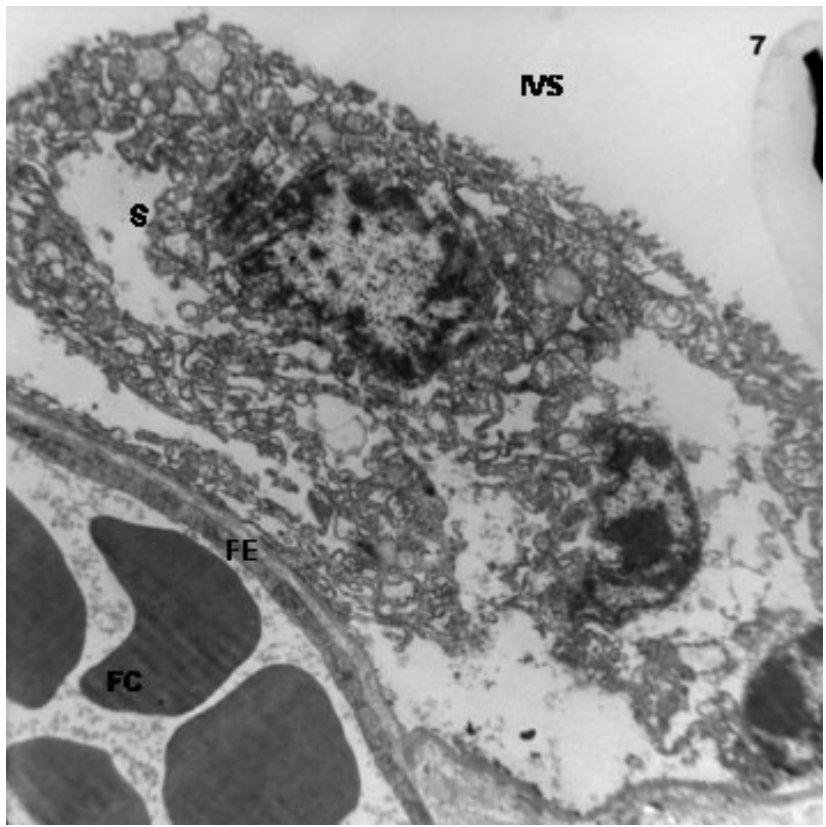

Fig. 2d. Syncytial necrosis (X-1550).

Fig. 2. Electronmicrograph of a terminal villi in placenta of a woman with Gestational Diabetes Mellitus showing changes in the syncytium (S- Syncytiotrophoblast, MBS- Maternal Blood Sinus, ER- Endoplasmic Reticulum, BM- Basement Membrane, C- Cytotrophoblast, FV- fetal Vessel, FE- Fetal Endothelium, G- Glycogen Deposits, IVS- Intervillous Space)

cytotrophoblastic cells showed degenerative changes as evidenced by cytoplasmic rarefaction, loss of rough endoplasmic reticulum, smooth endoplasmic reticulum, distortion of mitochondria and aggregation of nuclear chromatin (Fig. 3c). Glycogen deposits were also found in it (Fig. 3d).
Trophoblastic basement membrane: In control placenta (Fig. 2a), well defined areas of syncytial basal lamina (lamina densa) was viewed in the cross section of the terminal villi. At some places vasculosyncytial membrane was seen, in which outer aspect of the endothelial basement membrane of the capillary was closely applied to the syncytial basement membrane (Fig. 


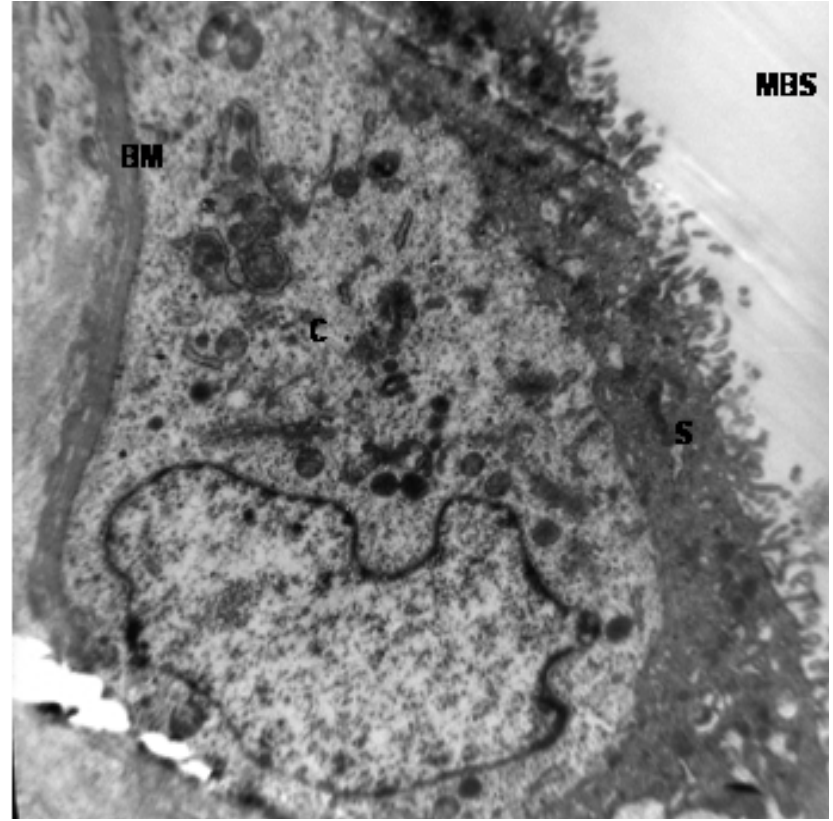

Fig. 3a. active cytotrophoblast (X-2650).

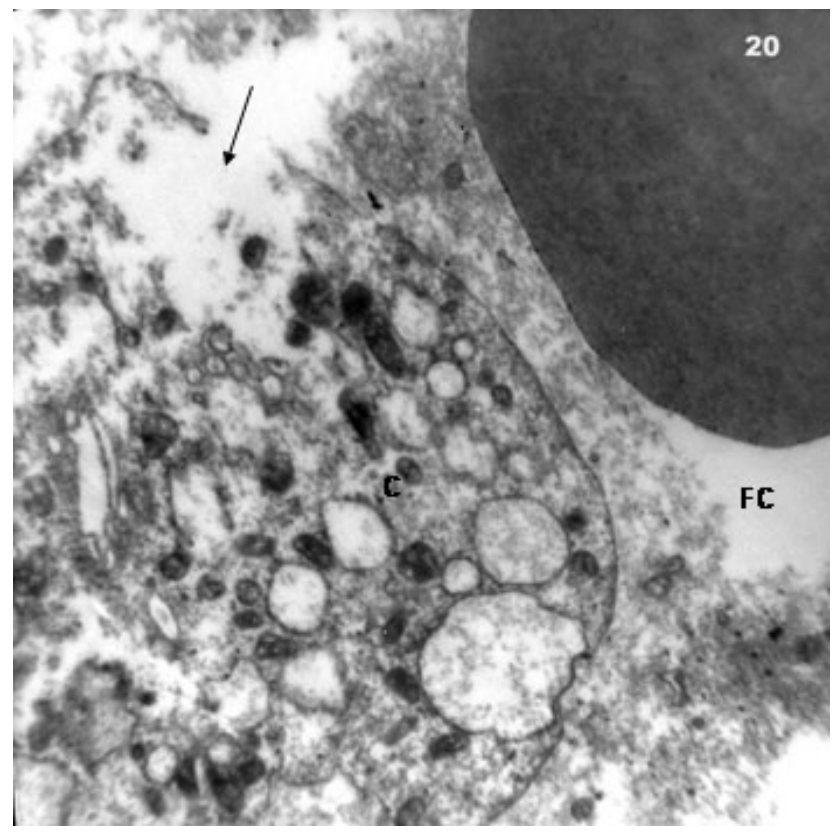

Fig. 3c. Degenarating cytotrophoblast (X-4600).

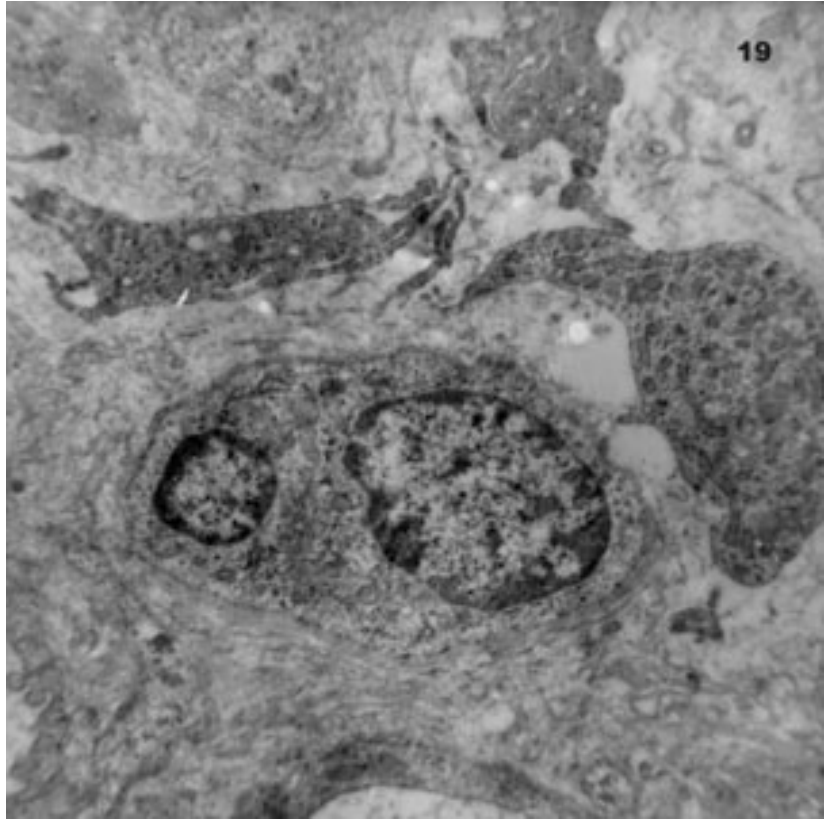

Fig. 3b. Double nucleoli (X -1950).

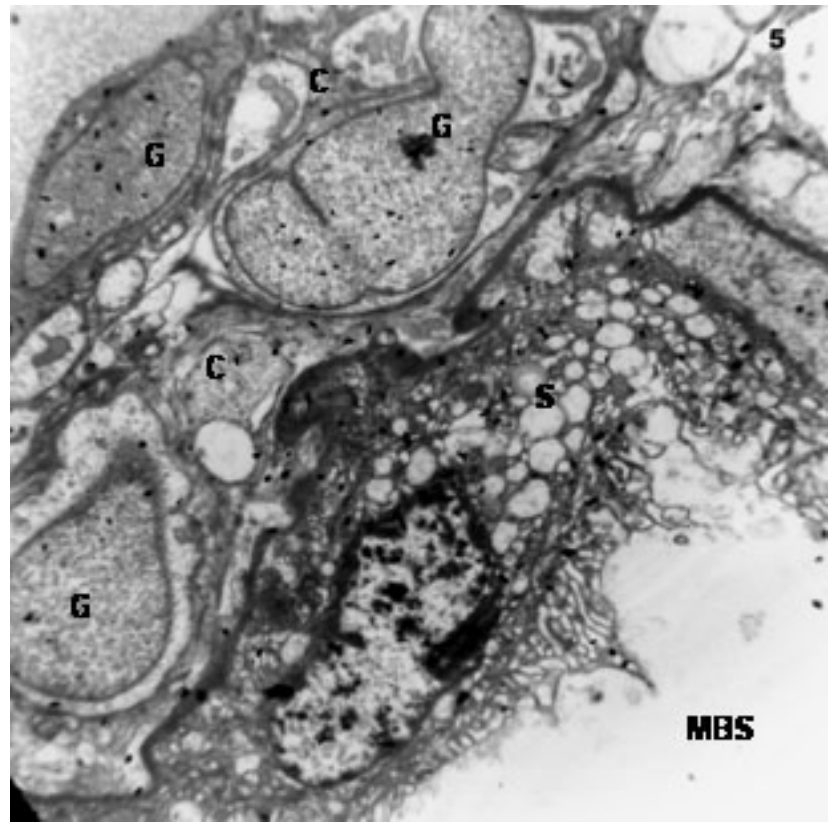

Fig. 3d. Glycogen deposits (X-1550).

Fig. 3. Electronmicrograph of a terminal villi in placenta of a woman with Gestational Diabetes Mellitus showing changes in the cytotrophoblast. (BM- Basement membrane, MBS- Maternal blood sinus, C- Cytotrophoblast, S- Syncytiotrophoblast, FC- fetal capillary, G- Glycogen)

4a). In diabetic pregnancies whether controlled on diet or insulin, there was focal increase in thickness of the syncytial basement membrane was seen in the majority of placentas (Fig. 4b).

Villous core: In control placenta (Fig. 2a), the villous core contained fibroblast with long cylindrical nuclei embedded in collagen fiber and fetal capillaries. In diabetic pregnancies controlled on diet, mild villous edema was observed in the villous core while in the placentas of diabetes controlled on insulin, marked villous edema was seen (Fig. 4c). Glycogen accumulations were seen in placentas of diabetes controlled on either diet or insulin (Fig. 4d). 
Villous capillary: Capillary basement membrane and endothelium was seen. In diabetic pregnancies, there were

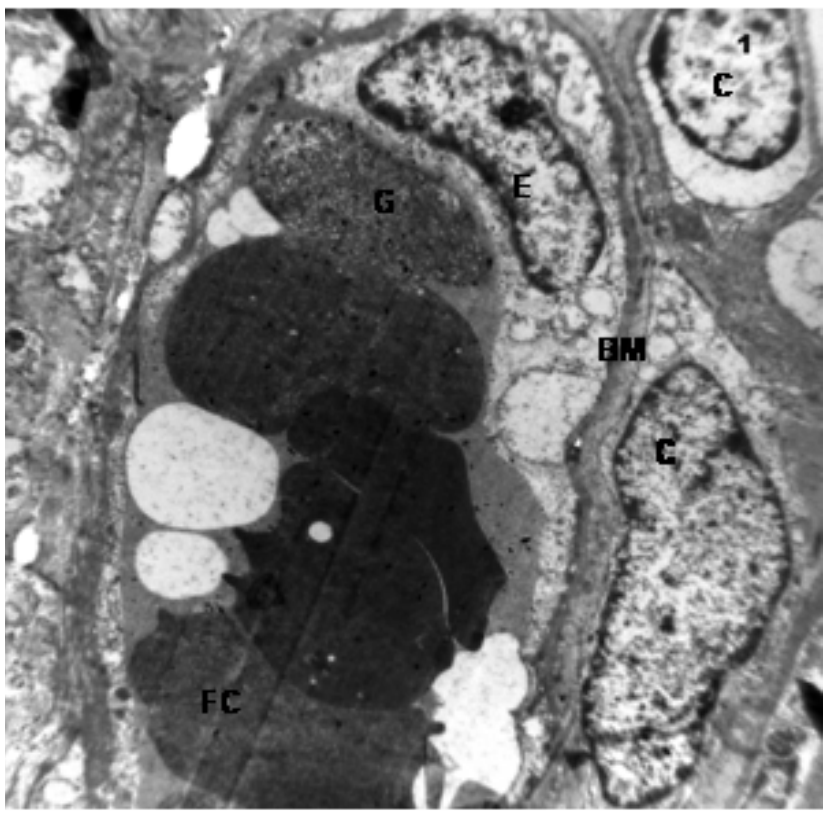

Fig. 4a. Basement membrane (X-1150).

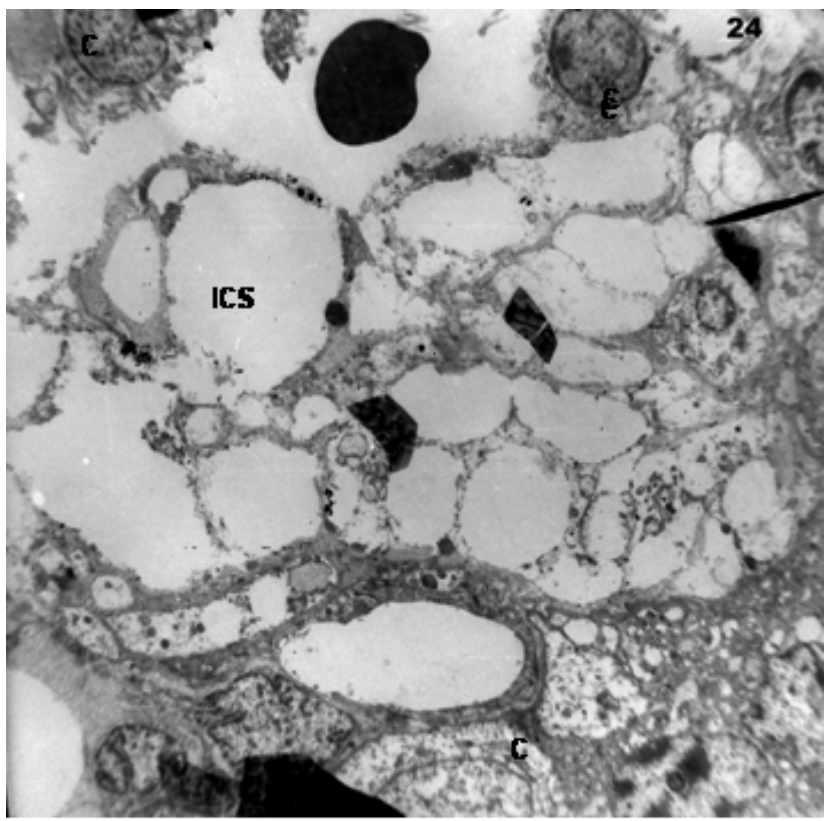

Fig. 4c. Edema in the villous core (X-870). regions of glycogen accumulation in the endothelium also (Fig. 4 a).

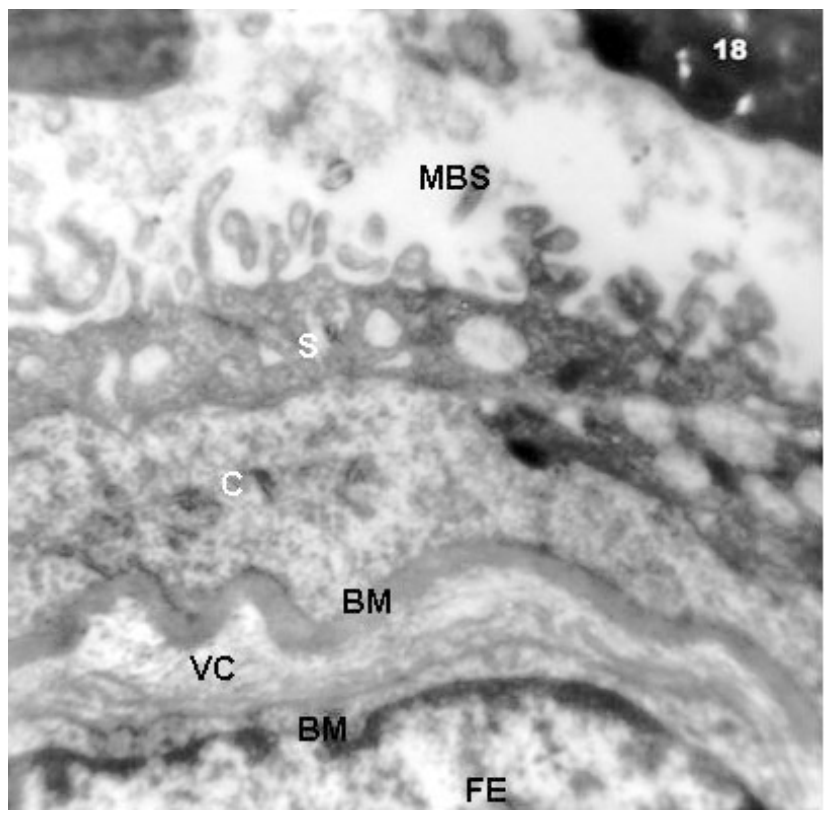

Fig. 4b. Basement membrane (X-6300).

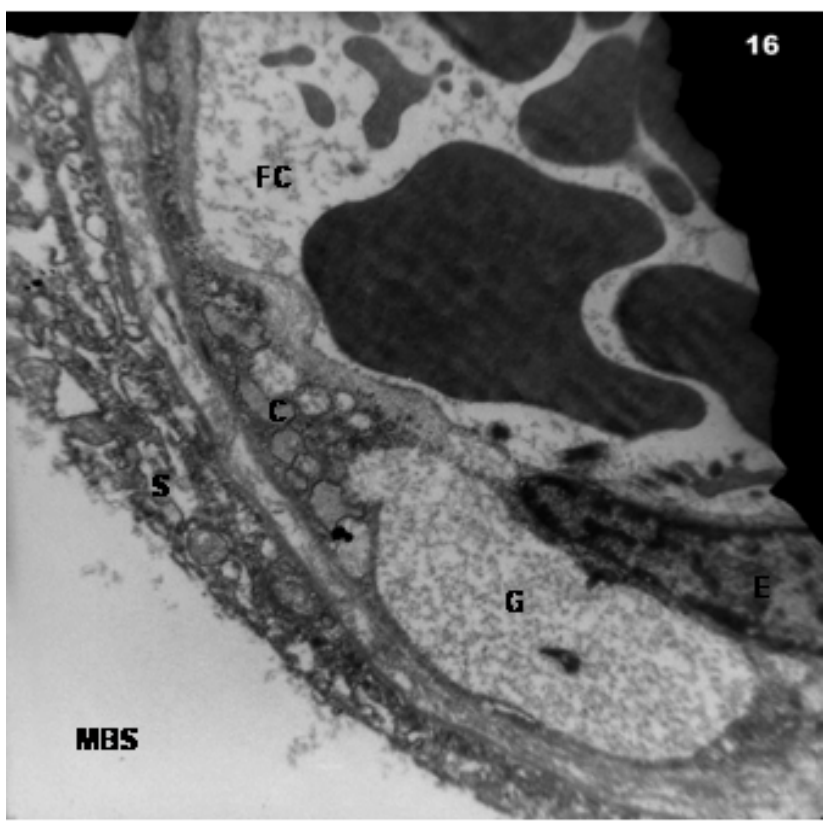

Fig. 4d. Glycogen deposit (X-2650).

Fig. 4. Electronmicrograph of a terminal villi in placenta of a woman with Gestational Diabetes Mellitus showing changes in the Basement membrane and villous core. (S- Syncytiotrophoblast, MBS- Maternal Blood Sinus, ER- Endoplasmic Reticulum, BM- Basement Membrane, C- Cytotrophoblast, FV- fetal Vessel, FE- Fetal Endothelium, G- Glycogen Deposits, IVS- Intervillous Space)

\section{DISCUSSION}

The physiological changes in the maternal metabolism during pregnancy with normal glucose tolerance provide both maternal and fetal-placental growth and energy requirements. The adaptations in the maternal metabolism 
occur throughout pregnancy that results in increased storage of fat in early pregnancy and increased availability of protein and carbohydrate in late pregnancy. In pregnancy with diabetes, there is already existing abnormality in carbohydrate metabolism and possibly protein and lipid metabolism (Patric et al., 1996). Despite the best glycemic control in the modern management of pregnancy, these biochemical changes still reflect adverse effect on fetus and placenta.

Reports on the pathology of placenta in diabetes mellitus are numerous but often contradictory. The inconsistency may be explained in part, by the fact that the category of diabetic pregnant women is very heterogeneous. The delineation of placental lesions in maternal diabetes has been also made unduly complex by the superimposed hypertensive and other associated complications. In the present study, complicating factors were excluded, and the degree of control of diabetes was considered to be excellent.

In our study, on gross observation, there was no major difference in the placenta of diabetic group and control group.

Under light microscopy, some workers have claimed that placentas of diabetic women show no unusual features (Cardwell). No major difference was observed in the microscopic changes of placentas in different groups according to White's classification of GDM (Marksheed et $a l$.). Some researchers have different opinion. As previously described, in our study, several differences were identified in the light microscopy of terminal villi of the placentas of GDM (Verma et al., 2010).

Increased number of syncytial nuclei was noted in the placentas of GDM. These nuclei showed chromatin clumping, a feature typical of senescence, and were usually arranged in clusters known as syncytial knots (Jones \& Fox; Yang, 1993). In the present study more numbers of syncytial knots were seen in the placentas of GDM controlled on insulin as compared to GDM controlled on diet and the control placentas.

There were reports on the changes observed in the villous core of the terminal villi like, villous immaturity (Yang). Fibrin thrombi, villous edema, hyperplasia and thickening of basal membrane of trophoblast was observed in the placenta of poorly controlled diabetes (al-Okail \& alAttas). Higher percentage of villi with stromal edema was also seen (Jácomo et al., 1976). In our study, fibrinoid necrosis, villous edema and villous fibrosis were observed especially in the placentas of GDM controlled on insulin. The placentas of GDM controlled on diet showed lesser areas of fibrinoid necrosis and showed more resemblance to the control group. Hyperplasia or thickenings of basal membrane of trophoblast were not observed in our study.
In diabetics $25 \%$ of villous surface is taken up by the capillary, while in normal placenta about $50 \%$ of the surface of the villous is taken up by the capillary surface (Geppert $e t$ al., 1982). Some literatures have reported the proliferation of small fetal vessels (Yang). Partial or total obstruction of the vascular lumen was also seen in the vessels of the villous trunk (Jácomo et al.). In the present study we did not notice any marked changes in the fetal capillary except proliferation of fetal capillaries in few placentas of GDM controlled on insulin.

Several differences were identified in the ultrastructure of the placental membrane of the terminal villi from diabetic placenta. Increased number of syncytiotrophoblast nuclei was noted in the diabetic group (Martin \& Spicer, 1973; Jones \& Fox). Small focal areas of necrosis, variable degree of dilatation of rough endoplasmic reticulum and autophagic vacuoles was also observed in few placentas (Jones \& Fox) In our study, we observed more number of syncytial knots, dilatation of rough endoplasmic reticulum and Glycogen deposits in the syncytium in majority of cases. In few cases focal areas of syncytial necrosis was seen in placentas of GDM controlled on insulin.

The number of cytotrophoblast, identified by the presence of nuclei, was increased in the diabetic group. In majority of cases the cytotrophoblast were of active type (Jones \& Fox; Kami \& Mitsui, 1984). Occasional cytotrophoblast also showed degenerative changes which may be due to failure of incorporation of cytotrophoblast into syncytiotrophoblast (Jones \& Fox; Benirschke \& Kaufmann, 1995). In our study, in most of the placentas, the cytotrophoblastic cells were of active type and showed variable amount of glycogen deposits. In some placentas of GDM controlled on insulin, cytotrophoblastic cells also showed degenerative changes.

Focal thickening of the villous trophoblastic basement membrane was observed (Jones \& Fox; Kami \& Mitsui). This study was in agreement with another study where thickening of basal membranes of trophoblast was seen (Pietryga et al.). In our study focal increase in the thickness of the syncytial basement membrane was seen in the majority of the placentas whether controlled on diet or insulin.

There was increased vascularization and glycogen accumulation within the stromal cells, corresponding to the higher glycogen content of diabetic placentas (Asmussen). In our study we noted that diabetic pregnancies controlled on diet, showed mild villous edema in the villous core, while in the placentas of diabetes controlled on insulin, marked villous edema was seen. Glycogen accumulations were seen in placentas of GDM, in both cases either controlled by either diet or insulin. 
The capillaries of the terminal villi showed separation of basal membranes in basal capillaries, distention and proliferation of endothelial cells, disarrangements of perivascular space and decrease in vascular surface of terminal villi. These changes were significant factor in contributing to fetal anoxia in pregnancy complicated by diabetes mellitus (Pietryga et al.). The endothelial cells of the villous capillaries appeared immature but no evidence of immune complex deposition was seen in the vessels (Jones \& Fox). In the present study, no such changes were observed in the fetal capillaries in the diabetic pregnancies, except accumulation of glycogen in the endothelium.

It is concluded that the placentas of diabetic pregnancies controlled on insulin showed a consistent pattern of abnormalities like glycogen deposits in all layers of the placental membrane, villous edema and focal thickening of trophoblastic basement membrane which ultimately leads to increase in the thickness of placental membrane. Degenerative changes were also seen in the syncytiotrophoblast and cytotrophoblast along with compensatory cytotrophoblastic hyperplasia. All these abnormalities were not present in every diabetic placenta but they were not completely absent in any of them. Each of these abnormalities was also seen, but to a much more limited extent in placentas from GDM controlled on diet. It should be noted that the placenta of women receiving insulin showed more changes in the placental membrane on ultrastructural examination as compared to those whose blood sugar was controlled by diet alone. Considering these changes, it would be logical to assume that the less severe and better controlled the diabetic pregnancies, less striking would be the placental abnormalities. The present study also indicates that such changes still occur to certain degree even the blood sugar level is well controlled either by diet or insulin. Hence, elimination of hyperglycemia will not absolutely prevent the development of placental abnormalities, and these may be due to some unknown constitute factor of the diabetic state which is only partially influenced by the diet or insulin.

VERMA, R.; MISHRA, S.; KAUL, J. M. Cambios ultraestructurales en la membrana placentaria en embarazos asociados con la diabetes. Int. J. Morphol., 29(4):1398-1407, 2011.

RESUMEN: La placenta es el registro más preciso de la experiencia prenatal infantil. Si la placenta se examina minuciosamente después del parto, ésta proporciona una visión más acabada de la salud prenatal de la madre y el bebé. El peso de la placenta es mayor en el embarazo con diabetes en comparación con el embarazo normal. Para estudiar los cambios celulares que podrían contribuir a un mayor peso de la placenta en los embarazos diabéticos, se llevó a cabo un análisis a través de microscopía óptica y electrónica. Fueron seleccionados 20 embarazos únicos complicados con diabetes mellitus gestacional (12 controlados por dieta, 8 controlado por insulina) y comparados con un grupo control. Las muestras de tejido fueron procesadas y analizadas. La placenta de los embarazos diabéticos no mostró ninguna anormalidad macroscópica, pero el examen por microscopía de luz reveló lesiones como nudos sinciciales, necrosis fibrinoide, edema velloso, fibrosis de las vellosidades y proliferación capilar. La microscopía electrónica de transmisión (TEM) mostró cambios en casi todas las capas de la membrana sincitiotrofoblástica, es decir, la placenta, citotrofoblasto, membrana basal trofoblástica y capilares fetales. Estos cambios se observaron en la placenta de ambos grupos de pacientes donde el nivel de azúcar en la sangre se controló mediante dieta o insulina, pero en grado diferente. Esto indica que el control de la hiperglicemia sólo impide parcialmente el desarrollo de anormalidades en la placenta, las cuales deben ser causadas por algún otro factor constituyente del estado diabético.

PALABRAS CLAVE: Diabetes mellitus gestacional; Microscopía electrónica de transmission; Membrana placentaria.

\section{REFERENCES}

al-Okail, M. S. \& al-Attas, O. S. Histological changes in placental syncytiotrophoblast of poorly controlled gestational diabetic patients. Endocr. J.; 41(4):355-60, 1994.

Asmussen, I. Ultrastructure of the villi and fetal capillaries of the placentas delivered by non-smoking diabetic women (White group D). Acta Pathol. Microbiol. Immunol. Scand. A, 90(2):95-101, 1982.

Benirschke, K. \& Kaufmann, P: Histopathological approach to villous alterations. In: Pathology of the Human placenta. 3rd Edn. New York, Springer-Verlag, 1995. pp.404-23.
Burstein, R.; Berns, A. W.; Hirata, Y. \& Blumenthal, H. T. A comparative histo- and immunopathological study of the placenta in diabetes mellitus and in erythroblastosis fetalis. Am. J. Obstet. Gynecol., 86:66-76, 1963.

Burstein, R.; Soule, S. D. \& Blumenthal, H. T. Histogenesis of pathological processes in placentas of metabolic disease in pregnancy. II. The diabetic state. Am. J. Obstet. Gynecol., 74(1):96-104, 1957.

Cardwell, B. S. The infants of diabetic mothers; a morphological study. J. Obstet. Gynaecol. Br. Emp., 60(6):834-53, 1953. 
Clavero-Nunez, J. A. The placenta in diabetes. Rev. Iber. Endocrinol., 10:73-80, 1963.

Dashkevich, O. V. \& Sechonov, I. M. The morphology of placenta in diabetes mellitus. Arkh. Pat., 26:7, 1964.

Dutta, D. C. Medical and surgical illness complicating pregnancy. In: Text Book of Obstetrics. 6th Ed. Calcutta, New Central Book Agency (P) Ltd., 2004. pp.284-90.

Fletcher, A. B. The infant of diabetic mother. In: Neanatology Pathophysiology and Management of the Newborn. Philadelphia, Lippincott, 1981. pp.287-302.

Geppert, M.; Peters, F. D. \& Geppert, J. Histomorphometry of the vascularization of the placental villi in diabetic pregnant women. Geburtshilfe Frauenheilkd., 42(8):628-32, 1982.

Holzner, H. J. \& Thalhammer, O. Zur Histologie und Histochemie der Placenta bei Diabetes Mellitus und Schwangerschaftglykosurie. Wein Klin. Wschr., 77:1024, 1965.

Horky, Z. Die quantitativen veranderungen der Vaskularisation der Zotten in der diabetischen Placenta. Zbl. Gynaek., 86:8, 1964.

Hughes, E. C. The placenta as it applies to the practice of obstetrics. South Med. J., 54:610-9, 1961.

Jácomo, K. H.; Benedetti, W. L.; Sala, M. A. \& Alvarez, H. Pathology of the trophoblast and fetal vessels of the placenta in maternal diabetes mellitus. ActaDiabetol. Lat., 13(5-6):21635,1976

Jones, C. J. \& Fox, H. Placental changes in gestational diabetes. An ultrastructural study. Obstet. Gynecol., 48(3):274-80, 1976.

Kami, K. \& Mitsui, T. Ultrastructural observations of chorionic villi at term in diabetic women. Tokai J. Exp. Clin. Med., 9(1):53-67, 1984.

Marksheed, M.; Musini, V. M.; Ahmed, M. A. \& Al-Harmi, J. Placental pathology in relation to the White's classification of diabetes mellitus. Arch. Gynecol. Obstet., 266(3):136-40, 2002.

Martin, B. J. \& Spicer, S. S. Ultrastructural features of cellular maturation and aging in human trophoblast. J. Ultrastruct. Res., 43(1):133-49, 1973

Patric, M. C.; Mark, B. L. \& Steven, G. Diabetes Mellitus. In: Reproductive endocrinology, surgery and technology. Philadelphia, Lippincott, 1996. pp.1710-20.

Pietryga, M.; Biczysko, W.; Wender-Ozegowska, E.; Brazert, J.; Biegan'ska, E. \& Biczysko, R. Ultrastructural examination of the placenta in pregnancy complicated by diabetes mellitus. Ginekol. Pol., 75(2):111-8, 2004.

Sani, G. \& Bottigliani, F. Studio isto fungionale della placenta nel diabete mellito. Riv. Ital. Ginec., 48:283, 1964.
Verma, R.; Mishra, S. \& Kaul, J. M. Cellular changes in the Placenta in Pregnancies Complicated with Diabetes. Int. J. Morphol., 28(1):259-64, 2010.

Yang, H. X. Placental pathology in gestational diabetes. Zhonghua Fu Chan Ke Za Zhi, 28(12):714-6, 1993.

\author{
Correspondence to: \\ Dr. Ranjana Verma \\ Department of Anatomy \\ Maulana Azad Medical College \\ New Delhi-110002 \\ INDIA
}

Email abharanjana@yahoo.com

Received: $30-12-2010$

Accepted: 22-08-2011 